\title{
Los derechos de libertad sindical en la Constitución chilena
}

\author{
Irene Rojas Miño*
}

\begin{abstract}
RESUMEN
A partir del fundamento general de la libertad sindical y del contenido de los derechos que lo integran, como también de la evolución que han tenido los textos constitucionales chilenos en el ámbito de los derechos sindicales, en este trabajo se analizan las diversas posiciones de la doctrina laboralista respecto de la cobertura constitucional de los derechos de libertad sindical y el contenido de estos derechos en el texto constitucional, como también la eficacia y vigencia de estos derechos en el sistema de relaciones laborales. Finalmente se plantean algunas hipótesis que permitan explicar la limitada eficacia de los derechos de libertad sindical en el sistema jurídico chileno.
\end{abstract}

Libertad sindical - Constitución - derechos sindicales

\section{Freedom of association in the chilean Constitution}

\begin{abstract}
Starting from the general foundation of freedom of association and its contents, as well as the evolution that chilean constitutional texts have had regarding collective rights, this work analyzes the different positions of labor doctrine about freedom of association constitutional coverage, its contents within the constitutional text and the efficacy and validity of this right in the labor relations system. Finally, bypothesis are given to allow to explain the limited efficacy of freedom of association in the chilean juridical system.
\end{abstract}

Freedom of association - Constitution - collective rights

* Doctora en Derecho, Universidad de Valencia. Profesora de Derecho, Universidad de Talca. Correo electrónico: irojas@utalca.cl.

Artículo recibido el 10 de octubre de 2015 y aceptado para su publicación el 1 de marzo de 2017. 


\section{INTRODUCCIÓN}

$\mathrm{E}$ 1 principio universal de libertad sindical acoge como derechos fundamentales los de sindicación, de negociación colectiva y de huelga, existiendo al respecto un acuerdo internacional de que la vigencia de estos derechos constituye una exigencia de los sistemas de gobiernos democráticos y pluralistas.

Es posible preguntarse si estos derechos están reconocidos en la Constitución chilena y cuál es el contenido que en ella tienen. Cierto es que estas preguntas podrían estar de más, en cuanto la doctrina, al menos la laboralista, plantea la tesis mayoritaria del reconocimiento constitucional de algunos o de todos los derechos de libertad sindical. Sin embargo se da cuenta de la vulneración a la libertad sindical por parte del modelo legal de relaciones laborales y ello en conformidad con lo que han señalado en reiteradas ocasiones los órganos de aplicación y control de las normas de la Organización Internacional del Trabajo (en adelante, OIT). Por consiguiente, la segunda interrogante plantea cuál es el alcance que estos derechos tienen en el sistema de relaciones laborales y, ciertamente, cómo se explicaría esta supuesta falta de eficacia de las garantías constitucionales respecto de la libertad sindical.

A partir del fundamento general de la libertad sindical y del contenido de los derechos que lo integran y, además, de la evolución que han tenido los textos constitucionales chilenos en el ámbito de los derechos sindicales, en este trabajo se analizan las diversas posiciones de la doctrina laboralista acerca de la cobertura constitucional de los derechos de libertad sindical y el contenido de estos derechos en el texto constitucional, como también la eficacia y vigencia de estos derechos en el sistema de relaciones laborales. Finalmente se plantean algunas reflexiones que permitan explicar la limitada eficacia de los derechos de libertad sindical en el sistema jurídico chileno.

\section{Fundamentos Y CONTENIDOS DE LOS DERECHOS DE LIBERTAD SINDICAL}

Es cierto que los institutos del Derecho sindical - particularmente el sindicato, la negociación colectiva y la huelga - han tenido una evolución que va desde su prohibición en el origen del actual sistema económico y de relaciones laborales, pasando por el de la mera tolerancia, hasta su reconocimiento como derechos de libertad sindical, a partir del siglo veinte, los que serán el soporte de la autonomía colectiva y, por consiguiente, de la segunda fuente del Derecho del Trabajo. En efecto, en la perspectiva jurídica, tanto del Derecho del trabajo, en general, como del Derecho sindical, en particular, importa la noción de autonomía colectiva, esto es, la potestad de los sujetos colectivos ...de representación y defensa de los intereses contrapuestos de trabajadores y empleadores (...) para la autorregulación de los mismos ${ }^{1}$, concepto que también comprende la autonomía institucional, la normativa y la autotutela, esta última como poder de defensa de los

\footnotetext{
${ }^{1}$ Palomeque, M., Derecho Sindical Español, Ed. Tecnos, Madrid, Quinta Edición revisada, 1994, p. 35.
} 
intereses del grupo por medios de acción directa como es la huelga ${ }^{2}$. Por lo demás, el reconocimiento de la huelga como derecho ....se ha convertido en la marca distintiva del derecho del trabajo en los sistemas democráticos ${ }^{3}$, en cuanto ...la superioridad de Estado-providencia sobre los estados totalitarios no ha residido en la concesión de protecciones sociales (...), sino en la garantía de derechos de acción colectiva que permitan a los dominados objetar a los dominantes su propia concepción de un orden justo ${ }^{4}$.

De esta manera, el principio de libertad sindical se concibe como los derechos y garantías de los trabajadores y de sus organizaciones para constituir organizaciones sindicales, afiliarse a ellas y desarrollar actividad sindical para la defensa de sus intereses, entre los que se cuentan, necesariamente, los derechos de negociación colectiva y de huelga ${ }^{5}$. Así lo ha asumido la doctrina de la OIT a partir de su Carta fundacional y de los Convenios concernientes a libertad sindical ${ }^{6}$, y la doctrina científica en el Derecho comparado $^{7}$ Sin embargo, no se debe olvidar que el reconocimiento de este principio y de los derechos que lo integran también se plantea en otros tratados internacionales sobre derechos fundamentales, como es en la Declaración Universal de los Derechos Humanos de Naciones Unidas, de 1948, que en su Artículo 23 apartado $4^{\circ}$ establece toda persona tiene el derecho de fundar sindicatos y el de afiliarse a estos para la defensa de sus intereses, el Pacto de Derechos Civiles y Políticos ${ }^{8}$ y el Pacto de Derechos Económicos, Sociales y Culturales?.

Pero, en definitiva, han sido los Convenios de OIT los que han definido el contenido de estos derechos de libertad sindical, en especial los Convenios $n^{\circ} 87$, sobre derecho de sindicación (1948), y n ${ }^{\circ}$ 98, sobre protección del derecho de sindicación y fomento de la negociación colectiva (1949), además de otros tres importantes instrumentos acerca de esta materia: Convenios no 135 (1971), sobre los representantes de los trabajadores,

${ }^{2}$ Palomeque, M., cit., p. 35.

3 Supiot, A. "Informe de Síntesis", en Marzal, A. (editor) La buelga boy en el derecho social comparado, Ed, Bosch, Barcelona, 2005, p. 268.

${ }^{4}$ Supiot, A. cit., p. 268 ,

5 Preciso esta definición por una necesidad de concretar la idea de libertad sindical, a pesar de los inconvenientes que tiene encerrar el alcance de este principio. Como señala Plá, A ("Los sindicatos en Uruguay" en Pasco, M. y Ackerman, M. [coordinadores], Los Sindicatos en Iberoamérica, Ed. Aele, Lima Perú, 1988, pp 376), “...la plasticidad del concepto, revela una mayor elasticidad y amplitud que la realidad, siempre cambiante $y$ novedosa, del mundo del trabajo va creando siempre...".

${ }^{6}$ Comité de Libertad Sindical, OIT, La Libertad Sindical. Recopilación de decisiones y principios del Comité de Libertad Sindical del Consejo de Administración de la OIT, Quinta edición revisada, Oficina Internacional del Trabajo, Ginebra, 2006.

${ }^{7}$ Así en Europa, a vía de ejemplo, Giugni, G. en Italia (Diritto Sindacale, Cacucci editore, Bari, 1988 , pp. 51 y ss) y Sala, T., España (Derecho Sindical, Ed. Tirant lo Blanch, Valencia, 1998, pp. 41 y ss), y Ermida, O., en Uruguay (Sindicatos en Libertad Sindical, Ed. Fondo de Cultura Universitaria, 2da edición, Montevideo, 1988, p. 29).

${ }^{8}$ De Naciones Unidas, de 1966 y ratificado por el Estado de Chile en 1989, en cuanto reconoce el derecho de toda persona “... a fundar sindicatos y afiliarse a ellos para la protección de sus intereses”. (art. 22, párr. primero.

${ }^{9}$ De Naciones Unidas (y ratificado por el Estado de chile en 1989), en cuanto el artículo 8 expresamente reconoce el derecho de fundar organizaciones sindicales, de desarrollar actividad sindical y el derecho a huelga. 
$\mathrm{n}^{\circ} 151$ (1978) sobre las relaciones de trabajo en la administración pública, y n ${ }^{\circ} 154$ (1981) sobre el fomento de la negociación colectiva.

A estos instrumentos jurídicos debe sumarse la interpretación que han efectuado de los mismos los órganos de control de la OIT, en especial de la libertad sindical, tal cual son la Comisión de Expertos para la aplicación de Convenios y Recomendaciones (en adelante CEACR) y el Comité de Libertad Sindical (en adelante CLS); interpretación que es inescindible en la función del control del cumplimiento de los convenios internacionales del trabajo ${ }^{10}$ y que ha generado una auténtica doctrina jurisprudencial, la que ha sido sistematizado en sucesivas publicaciones ${ }^{11}$. Si bien estos pronunciamientos emanan de competencias distintas ${ }^{12}$, los fundamentos normativos son similares y, además, ambos se fundan en los mismos principios, que tienen un alcance universal... ${ }^{13}$, por lo que la CEACR y el CLS tienen en cuenta mutuamente sus pronunciamientos ${ }^{14}$.

Es cierto que por parte de específicas entidades se ha cuestionado el alcance jurídico de dicha interpretación, como fue la del Grupo de los Empleadores en la reunión de la Comisión de Aplicación de Normas de la Conferencia Internacional del Trabajo, celebrada en junio de 2012, controversia que fue planteada respecto de la CEACR en lo referido al reconocimiento del derecho de huelga en el Convenio 87; aunque dicho cuestionamiento fue medianamente superado en la Reunión Tripartita de febrero de $2015^{15}$, mediante una Declaración Conjunta del grupo de empleadores y del grupo de trabajadores se reconoce el mandato de la CEACR ${ }^{16}$.

${ }^{10}$ Como sostiene Ackerman, Mario, "Carácter y eficacia de los pronunciamientos de la Comisión de Expertos en la aplicación de convenios y recomendaciones de OIT" (en http://colegioabogadosavo.org.ar/ laboral/contenido/documentos/77.pdf, visitado el 10 de agosto de 2016).

${ }^{11}$ La de la CLS en OIT, Comité de Libertad Sindical, La Libertad Sindical..., cit., 2006. La de la CEACR, en OIT, Comisión de Expertos en la Aplicación de Convenios y Recomendaciones (Conferencia Internacional del Trabajo), 81.a reunión, 1994, Informe III (Parte 4B), Ginebra, Edita Oficina Internacional del Trabajo.

${ }^{12}$ La CEACR, revisa la Memoria de cada Estado en el ámbito del Procedimiento Regular, mientras que el CLS se hace cargo del Procedimiento de Reclamación por parte de organizaciones de trabajadores y de empleadores por vulneraciones a los Convenios de Libertad Sindical.

13 Ídem, p. 9.

${ }^{14}$ OIT, Comisión de Expertos en la Aplicación de Convenios y Recomendaciones, cit., pp. 8-9.

15 Convocada por el Consejo de Administración de la OIT, Reunión Tripartita relativa al Convenio sobre la libertad sindical y la protección del derecho de sindicación 1948 (núm. 87) en relación con el derecho de huelga y las modalidades y prácticas de la huelga a nivel nacional, Ginebra, 23-25 de febrero de 2015, en http://www.ilo.org/wcmsp5/groups/public/---ed_norm/---relconf/documents/meetingdocument/ wcms_346766.pdf, visitado el 10 de agosto de 2016.

${ }^{16}$ En tal sentido se plantea: La Comisión de Expertos realiza un examen técnico e imparcial de la manera en que los Estados Miembros aplican los convenios en la legislación y en la práctica, teniendo en cuenta las diferentes realidades y sistemas jurídicos nacionales. Al hacerlo, debe determinar el alcance jurídico, contenido y significado de las disposiciones de los convenios. Sus opiniones y recomendaciones no son vinculantes y buscan orientar las acciones de las autoridades nacionales. El carácter persuasivo de esas opiniones y recomendaciones se deriva de la legitimidad y racionalidad de labor de la Comisión que se basa en su imparcialidad, experiencia y competencia técnica. Véase (Ibíd.), Anexo I. Iniciativa relativa a las normas de la OIT - Declaración conjunta del grupo de los trabajadores y del grupo de los empleadores (23 de febrero de 2015). 
En definitiva, la doctrina y los diversos sistemas jurídicos, tanto nacionales como ${ }^{17}$ internacionales ${ }^{18}$, han asumido la "jurisprudencia" que emana de los pronunciamientos de la CEACR y del CLS, como bien se ha sintetizado en tres argumentos ${ }^{19}$ otorgados por el Centro de Formación de la OIT ${ }^{20}$ : (1) la labor de los órganos de control constituye una lectura particularmente autorizada de los convenios internacionales del trabajo ${ }^{21} ;(2)$ la labor de los órganos de control constituye una lectura válida, hasta que se determine lo contrario por parte de la Corte Internacional de Justicia ${ }^{22}$; y (3) en conformidad con la Convención de Viena, los tratados deben aplicarse de buena fe, lo que incluye someterse a los órganos de control definidos debiendo tomar en cuenta sus observaciones y recomendaciones ${ }^{23}$.

Por consiguiente, de acuerdo con las fuentes señaladas, los convenios de OIT y la interpretación efectuada por los órganos señalados, el derecho de sindicación comprende ...por lo menos la libertad para constituir sindicatos, organizarlos y afiliarse a ellos, así como la adecuada protección al ejercicio de la libertad sindical ${ }^{24}$, junto con los derechos de acción sindical. Precisamente, con los derechos de organización interna -o autonomía sindicalse reconoce a los sindicatos la autonomía de acción: el derecho de las organizaciones a organizar su administración, sus actividades y de formular su programa de acción; es decir, el derecho a desarrollar la actividad sindical, perspectiva en que adquieren importancia fundamental dos derechos: el de negociación colectiva -...el derecho de negociar libremente ... constituye un elemento esencial de la libertad sindical ${ }^{25}$ - y el de huelga - el derecho de buelga de los trabajadores y sus organizaciones constituye uno de los medios esenciales de que disponen para promover y defender sus intereses profesionales- ${ }^{26}$.

A su vez, el derecho a negociar colectivamente es esencial en el marco de la libertad sindical. Al efecto, el Convenio 98 estableció en su artículo 4 que Deberán adoptarse

\footnotetext{
${ }^{17}$ En este sentido y como lo señala el Centro Internacional de Formación de OIT (Derecho Internacional del Trabajo y Derecho Interno. Manual de Formación para jueces, juristas y docentes en derecho, (Director) Xavier Beaudonet, Ed. Cintr Internacional de Formación OIT. Turín, 2009 [en http://es.slideshare.net/ GabrielBenavides/dit-y-derecho-interno-manuel-de-formacion-para-jueces-y-juristas-8638515, visitado el 10 de agosto de 2016], pp. 95-97), tribunales de justicia de Australia, Sudáfrica, Argentina y Perú, entre otros, han utilizado dicha doctrina.

${ }^{18}$ Así (Ídem, p. 98) la Corte Interamericana de Derecho Humanos, en el caso Baena Ricardo y otros, de 2 de febrero de 2001, y el Tribunal Europeo de Derechos Humanos, respecto de restricciones de empleo para antiguos agentes de la KGB, de 27 de julio de 2004.

19 Como señalan Leyton, Jorge y Azócar, Rodrigo, "El valor jurídico de los pronunciamientos de los órganos de control de la OIT en Chile", Ponencia libre presentada en Cuartas Jornadas de Derecho del Trabajo de la Universidad de Talca: "Los derechos del trabajo en la Constitución, en especial los de libertad sindical", Santiago, 14 y 15 de julio de 2016.

${ }^{20}$ OIT, Centro Internacional de Formación de la OIT, “Derecho Internacional...”, cit., pp. 93-95.

21 Ídem, pp. 93

${ }^{22}$ Ídem, pp. 93-94. En conformidad con el Artículo 37 de la Constitución de la OIT, corresponde a la Corte Internacional de Justicia dar la interpretación definitiva.

23 Ídem, pp. 94-95.

${ }^{24}$ Ermida, O., cit., p. 29

${ }^{25}$ Comité de Libertad Sindical, cit., p. 171.

${ }^{26}$ Comité de Libertad Sindical, cit., p. 111.
} 
medidas adecuadas a las condiciones nacionales, cuando ello sea necesario, para fomentar y estimular entre los empleadores y las organizaciones de empleadores, por una parte, y las organizaciones de trabajadores, por otra, el pleno desarrollo y uso de procedimientos de negociación voluntaria, con objeto de reglamentar, por medio de contratos colectivos, las condiciones de empleo. Por su parte, el Convenio 154 reiteró tal idea y estableció además diversas medidas de fomento de la negociación colectiva.

El tercer derecho esencial de la autonomía sindical es el derecho de huelga. Este derecho, en el concepto de libertad sindical, tiene un contenido amplio. En todo caso, durante los últimos años se han planteado discrepancias al interior de la OIT acerca del alcance del derecho de huelga - ello a partir de una objeción de la parte empresarial a la interpretación de la misma ${ }^{27}$ - y el dato cierto es que se presenta una ausencia de una exposición explícita y declarada de este derecho en un instrumento internacional ${ }^{28}$. No obstante, los diversos órganos de la OIT dan cuenta de este derecho en los instrumentos fundantes de esta organización como de los convenios de libertad sindical han señalado que el derecho de buelga es corolario indisociable del derecho de sindicación protegido por el Convenio núm. $87^{29}$. Además, en la reunión de febrero de 2015 de OIT, los representantes de los gobiernos han reiterado la valoración del derecho de huelga ${ }^{30}$, y en la misma oportunidad los representantes de empleadores y de trabajadores por medio de la declaración conjunta han insistido en el derecho de los trabajadores y de los empleadores a emprender acciones colectivas en defensa de sus intereses legítimos ${ }^{31}$.

\section{LOS DERECHOS DE LIBERTAD SINDICAL EN LA EVOLUCIÓN CONSTITUCIONAL CHILENA}

Si bien la constitucionalización de los derechos laborales se plantea en las primeras décadas del siglo veinte, y que se manifiesta en la constitución de Querétaro (México, 1917) y Weimar (Alemania, 1919), incorporando esta última diversas dimensiones del

${ }^{27}$ En la citada reunión de junio de 2012 llama la atención que la observación del grupo de empleadores se plantee solo respecto de la CEACR y no así al CLS, en circunstancias de que el contenido de la doctrina es similar. Se ha señalado que el efecto es distinto, más amplio el de la primera entidad -la CEACR-en cuanto tiene que ver con decisiones de Estado, mientras que las del CLS solo afectan al caso específico. Pero debe considerarse que también la integración de dichos órganos es diversa. En la CEACR solo hay expertos, principalmente juristas, en el CLS hay representación de los tres estamentos, gobiernos, trabajadores y empleadores.

${ }^{28}$ Bellace, J., "La OIT y el derecho de huelga", en Revista Internacional del Trabajo, Vol. 133 (2014), núm 1, p. 32.

${ }^{29}$ Comité de Libertad Sindical, cit., p. 11.

${ }^{30}$ Como plantea la Declaración del Grupo Gubernamental, de 23 de febrero de 2015, en Reunión Tripartita, convocada por el Consejo de Administración de OIT (cit., Anexo II).

${ }^{31}$ Como plantea la Declaración del grupo de los trabajadores y del grupo de los empleadores, de 23 de febrero de 2015, en Reunión Tripartita, convocada por el Consejo de Administración de OIT (cit., Anexo I). 
principio de libertad sindical ${ }^{32}$, el texto original de la Constitución chilena de 1925 excluyó estos últimos derechos, reconociendo solo algunos de corte individual, sumando además específicos derechos de seguridad social de orden no contributivo ${ }^{33}$. Será solo en 1971, con la modificación efectuada en la Ley 17.398, que la Constitución, junto con garantizar nuevos derechos laborales individuales ${ }^{34}$, asume el reconocimiento de los derechos de libertad sindical referidos a los de sindicación y de huelga.

En efecto, esta reforma constitucional reconoció el derecho a sindicarse en el orden de sus actividades o en la respectiva obra o faena (...) en conformidad a la ley, como también el derecho de constituirse en sindicato sin autorización previa ${ }^{35}$ y el de la libertad del sindicato para cumplir sus propios fines. El derecho de huelga, por su parte, se reconoce como tal, aunque ... en conformidad a la ley. Y si bien el derecho de negociación colectiva no integró expresamente la garantía de los derechos de libertad sindical, en una perspectiva actual debería ser considerado en el ámbito del derecho del sindicato para cumplir sus propios fines, como ha sostenido reiteradamente la Organización Internacional del Trabajo por medio de sus órganos de interpretación ${ }^{36}$.

Sin embargo, llama la atención los términos en que este texto constitucional reconoció el derecho de sindicación, en cuanto lo limitó a específicos niveles de la estructura económica y que corresponden al orden de las actividades o de la respectiva industria o faena, cuestión que ciertamente iría en contra de la libertad sindical.

Unida a esta restricción del principio de libertad sindical por parte del Estado de Chile, la interrogante que surge es por qué este no había ratificado los instrumentos jurídicos de OIT respecto de la materia, particularmente el Convenio 87 de 1948 y el Convenio 98 de 1949, en circunstancias de que Chile ha sido miembro de tal entidad internacional desde su creación en $1919^{37}$.

${ }^{32} \mathrm{Al}$ respecto, véase de Maestro, G., La constitución del trabajo en el estado social (Ed. Comares, Granada, 2001, 331 páginas), particularmente el Capítulo 2 "Weimar y la construcción frustrada del Estado Social”, pp. $9-30$.

${ }^{33}$ En efecto, el artículo 10, N 14.o, del texto original de la Constitución Política de 1925 garantizaba a todos los habitantes la protección al trabajo, a la industria, y a las obras de previsión social... (inciso $1^{\circ}$ ). Además, ninguna clase de trabajo o industria puede ser probibida, a menos que se oponga a las buenas costumbres, a la seguridad o a la salubridad pública, o que lo exija el interés nacional y una lei lo declare así. (inciso $3^{\circ}$ ). Asimismo, es deber del Estado velar por la salud pública y el bienestar bijiénico del país. Deberá destinarse cada año una cantidad de dinero suficiente para mantener un servicio nacional de salubridad... (inciso $4^{\circ}$ ).

${ }^{34}$ Como son la libertad de trabajo y su protección, Asimismo, se garantiza el derecho al trabajo, en cuanto Toda persona tiene derecho al trabajo, a la libre elección de este, a una remuneración suficiente que asegure a ella y a su familia un bienestar acorde con la dignidad humana y a una justa participación en los beneficios que de su actividad provengan (Art. 10, $\mathrm{N}^{\circ} 14$, inciso $1^{\circ}$ ). Además, se establece que ninguna clase de trabajo o industria será prohibido.

35 En cuanto expresamente se establece que los sindicatos y demás organizaciones sindicales gozarán de personalidad jurídica por el solo becho de registrar sus estatutos y actas constitutivas en la forma y condiciones que determine la ley (Art. 10, $\mathrm{N}^{\circ} 14$, inciso $3^{\circ}$ ), con lo que se supera la exigencia establecida en la ley laboral, entonces el Código del Trabajo de 1931, que requería la autorización administrativa.

${ }^{36}$ Comité de Libertad Sindical, cit., p. 171.

${ }^{37} \mathrm{Al}$ respecto, véase de Rojas M., I. "La legislación laboral en Chile en el ámbito de las relaciones colectivas de trabajo: control de la autonomía colectiva”, en Revista Ius et Praxis, Año 6, n 2, 2000, pp. 382- 
Posteriormente la Constitución de 1980 estableció un nuevo marco de los derechos colectivos del trabajo, aunque el origen de este modelo es el Plan Laboral impuesto durante 1979, el que en lo pertinente modificó el acta Constitucional no 3 de 1976.

Como es sabido, en los primeros años del régimen militar la Constitución de 1925 es modificada en diversas materias, como es la referida a las garantías constitucionales mediante el Acta $\mathrm{N}^{\circ}$ 3, establecida en el D.L. 1552 de 1976. El texto original de esta Acta modificó sustancialmente las garantías del orden laboral, tanto en la dimensión individual $^{38}$ como en la dimensión colectiva. En esta última perspectiva, si bien se reitera el reconocimiento del derecho de sindicación en orden de las actividades y de las faenas, agrega una mayor sujeción al desarrollo que efectúe la ley ${ }^{39}$, adiciona el establecimiento de vías obligatorias de solución del conflicto ${ }^{40}$ y plantea la prohibición de la huelga en diversos sectores, entre ellos el de la administración pública ${ }^{41}$. Sin duda que este marco constitucional da cuenta de la propuesta institucionalizadora de sesgo corporativo que se plantea en el ámbito de las relaciones de trabajo en los primeros años del régimen militar ${ }^{42}$.

Pero será por medio del Plan Laboral que se establezca, en definitiva, el régimen constitucional de los derechos sindicales, en cuanto es el D.L. 2755 el que, junto con modificar el Acta $\mathrm{n}^{\circ} 3$, define dicho marco constitucional de las relaciones colectivas de trabajo, el que posteriormente reitera el texto constitucional de $1980^{43}$. Además, esta normativa constitucional del Plan Laboral es la que en términos expresos rige hasta

383. La vía de hipótesis plantea que no existía un real consenso respecto de algunos de los alcances del principio de libertad sindical, específicamente con la libertad de afiliación en la dimensión individual de este principio y con la pluralidad en la estructura sindical.

${ }^{38}$ Si bien se mantienen el derecho del trabajo, se agregan otros de corte liberal como es el de la libre elección del trabajo. Además se incorpora el derecho de participación en la empresa, dimensión que había estado ausente y que tiene un fugaz reconocimiento, en cuanto ya en 1979 es eliminado.

${ }^{39}$ De esta manera el derecho de sindicación se sujeta a los casos y en la formas que señale la ley (Art. 1, n. 22, inciso 1, Acta 3). Asimismo, se encarga a la ley, contemplar ...mecanismos que aseguren la autonomía de las organizaciones sindicales y su propio financiamiento (Art. 1, n. 22, inciso 3 del Acta 3). En todo caso, se reitera el acceso directo a la obtención de la personalidad jurídica de la organización sindical, ...por el solo hecho de registrar sus estatutos y actas constitutivas en un organismo autónomo en la forma que determine la ley (Art. 1 , n. 22, inciso $2^{\circ}$, del Acta 3 ).

40 Art. 1, n. 20, incisos 8 y 9 del Acta 3.

${ }^{41}$ El Art. 1, n. 20, inciso 10 del Acta 3 prescribe:

En ningún caso podrán declararse en huelga los funcionarios del Estado o de las Municipalidades, como tampoco las personas que trabajen en empresas que atiendan servicios de utilidad pública, o cuya paralización cause grave daño a la salud, al abastecimiento de la población, a la economía del país o a la seguridad nacional.

42 En efecto, entre 1975 y 1976, bajo la jefatura del Ministerio del Trabajo del general de la Fuerza Aérea, Nicanor Díaz Estrada, se planteó un proyecto de protección autoritaria de las relaciones laborales, característica que le confería un sesgo corporativo, planteándose una tesis que supone la integración en la empresa del capital y el del trabajo y que desconoce el conflicto o diferencias de intereses entre la dirección de la empresa y los trabajadores.

${ }^{43}$ En todo caso, es posible observar que a la fecha de dictación del D.L. 2755, de 1979, los aspectos del régimen sindical considerados en el proceso de elaboración de esta Constitución, particularmente el referido a la huelga, ya habían sido objeto de discusión. Al respecto, véase en lo pertinente, Actas de la Comisión Ortúzar (http://www.leychile.cl/Consulta/antecedentes_const_1980 (visitada el 21 de octubre de 2015). 
hoy, en cuanto la única modificación sustancial que en dicha materia efectuó el texto original de la Constitución de 1980 fue el de agregar la prohibición de los dirigentes de las organizaciones sindicales de intervenir en actividades político partidistas, prohibición que fue suprimida en la primera modificación constitucional de 1989 por la Ley 18.825 de 1989, producto de un acuerdo político aunque aún gobernaba el régimen militar.

En definitiva, el texto explícito de la Constitución establece las bases del marco de organización y de actuación de las organizaciones de trabajadores. Si bien se reconoce el derecho a constituir sindicatos, sujeta este derecho a la forma que establezca la ley ${ }^{44}, y$ además limita a que estas organizaciones puedan ...intervenir en actividades político partidistas $^{45}$; y las garantías se plantean respecto de otras materias: la voluntariedad en la afiliación ${ }^{46}$, la adquisición de la personalidad jurídica por el cumplimiento de exigencias objetivas $^{47}$ y la autonomía de estas organizaciones ${ }^{48}$. En el ámbito de la negociación colectiva solo reconoce este derecho en el nivel de la empresa, pero entrega a la ley tanto la posibilidad de excluir este derecho en específicos casos, como establecer el régimen jurídico de su ejercicio, limitando al efecto diversas dimensiones ${ }^{49}$. Más particular es aún la regulación de la huelga, en cuanto además de no garantizar el respectivo derecho, prohíbe la huelga en determinados sectores como es el de los trabajadores del Estado y de las municipalidades ${ }^{50}$.

\section{LAS TESIS DEL RECONOCIMIENTO DE LOS DERECHOS DE LIBERTAD SINDICAL EN LA CONSTITUCIÓN}

Es discutible que el texto explícito de la Constitución acoja los derechos de libertad sindical, si entendemos por tales los definidos en la doctrina de los derechos de libertad sindical, particularmente la emanada de la OIT y sus órganos de interpretación. Al efecto, la interrogante acerca del supuesto reconocimiento de los derechos de libertad sindical en la Constitución política ha sido enfrentada por la doctrina laboralista chilena,

${ }^{44}$ Art. 19, nro. 19, inciso 1.ro, primera parte, CP.

45 Art. 19, nro. 19, inciso 1.ro, parte final, CP.

${ }^{46}$ Art. 19, nro. 19, inciso 3.ro, parte final, CP.

${ }^{47}$ Art. 19, nro. 19, inciso 2.do, CP; en cuanto establece: Las organizaciones sindicales gozarán de personalidad jurídica por el solo becho de registrar sus estatutos y actas constitutivas en la forma y condiciones que determine la ley.

48 Art. 19, nro. 19, inciso 2.do, primera parte, CP.

${ }^{49}$ Así, el Art. 16, nro. 16, inciso 5.to, CP; establece que ...La ley establecerá las modalidades de la negociación colectiva y los procedimientos adecuados para lograr en ella una solución justa y pacífica. La ley señalará los casos en que la negociación colectiva deba someterse a arbitraje obligatorio, el que corresponderá a tribunales especiales de expertos cuya organización y atribuciones se establecerán en ella.

50 Así el Art. 16, nro. 16, inciso 6.to, CP. establece que No podrán declararse en huelga los funcionarios del Estado ni de las municipalidades. Tampoco podrán hacerlo las personas que trabajen en corporaciones o empresas, cualquiera que sea su naturaleza, finalidad o función, que atiendan servicios de utilidad pública o cuya paralización cause grave daño a la salud, a la economía del país, al abastecimiento de la población o a la seguridad nacional. La ley establecerá los procedimientos para determinar las corporaciones o empresas cuyos trabajadores estarán sometidos a la probibición que establece este inciso. 
la que plantea posiciones que van desde admitir los derechos de libertad sindical en el texto original de la Constitución, hasta las que solo asumen dicho reconocimiento una vez que se incorpora el mandato de integración de los tratados internacionales y que se lograría, en definitiva, con la ratificación de los Convenios 87 y 98 de la OIT, lo que ocurre en 1998. La primera tesis, la del reconocimiento explícito de los derechos de libertad sindical, sostiene que el texto constitucional acoge en los preceptos respectivos, particularmente los números 16 y 19 del Art. 19, los derechos de libertad sindical. Mientras que la segunda tesis, del reconocimiento vía incorporación de los tratados sobre derechos humanos, solo se habría alcanzado con la modificación constitucional de 1989, referida al inciso segundo al Art. 5 del texto constitucional ${ }^{51}$.

La tesis del reconocimiento constitucional explícito de los derechos de libertad sindical ha generado la adhesión de dos posiciones. La primera ${ }^{52}$ sostiene que el Art. 19 n. 16 de la Constitución representa el modelo de relaciones laborales que ostenta dicho código político, destacándose el reconocimiento del pluralismo social y la autonomía colectiva, entre otras materias ${ }^{53}$. Es importante destacar que esta posición analiza al efecto solo los derechos de negociación y de huelga, y ello lo hace sin confrontarlo con los convenios de la OIT y la interpretación que se ha efectuado de los mismos; además gran parte de su fundamentación dogmática la formula basada en la doctrina elaborada a partir del modelo constitucional español ${ }^{54}$, en circunstancias de que dicho modelo tiene bases distintas -0 , más bien, totalmente distintas - al modelo constitucional chileno ${ }^{55}$.

${ }^{51}$ En cuanto, al contenido ya establecido de dicho inciso $2^{\circ}$ del Art. 5 -El ejercicio de la soberanía reconoce como limitación el respeto a los derechos esenciales que emanan de la naturaleza bumana-, adiciona la siguiente declaración: Es deber de los órganos del Estado respetar y promover tales derechos garantizados por esta Constitución, así como por los tratados internacionales ratificados por Chile y que se encuentren vigentes.

52 Irureta, P., Constitución y Orden Público Laboral. Un análisis del art. $19 \mathrm{~N}^{\circ} 16$ de la Constitución chilena, Ed. Universidad Alberto Hurtado, Santiago, 2006, Nº 9, 233 páginas.

53 Irureta, P., cit., p. 30.

${ }^{54}$ Así, en el ámbito del derecho de negociación colectiva, esta posición afirma, entre otras dimensiones, que tendría el modelo constitucional chileno, ... que la Constitución legitima a la negociación colectiva como el conjunto idóneo de "reglas de acción y organización a través de las cuales los antagonistas sociales actualizan su poder autonómico colectivo"... (Irureta, cit, p. 162), citando el planteamiento de Sala, T., quien lo expone a propósito de la norma constitucional española ("El derecho constitucional a la negociación colectiva”, en Casas Ma. E., Durán, F. y Cruz, J., Las transformaciones del Derecho del Trabajo, en el marco de la Constitución española, Ed. La Ley, Madrid, pp. 319-328).

${ }^{55}$ En efecto, como señala Palomeque, M. (Los derechos laborales en la Constitución española, Centro de Estudios Constitucionales, Colección Cuadernos y Debates, n. 28, Madrid, 1991, 124 páginas), la Constitución española, que es de 1978, ... diseña ciertamente un modelo democrático de relaciones laborales, articulado sobre el reconocimiento de la libertad sindical, como derecho fundamental y el juego pleno de la autonomía colectiva... (p. 15).

Este modelo constitucional descansa sobre dos elementos básicos: En primer lugar, concepción dialéctica de las relaciones de trabajo y asignación al conflicto de un papel funcional dentro del esquema constitucional. En segundo término, la autonomía colectiva como pieza esencial del sistema normativo, en cuanto el modelo de relaciones laborales se funda en la regulación de las condiciones de trabajo por parte de los interlocutores sociales: la ley garantizará el derecho a la negociación colectiva laboral entre los representantes de los trabajadores y empresarios, así como la fuerza vinculante de los convenios (art. 37.1 CE.). 
La segunda posición al interior de esta primera tesis adiciona al reconocimiento explícito de todos o algunos derechos de libertad sindical en el texto constitucional, el del reforzamiento de tal perspectiva por la ratificación de los tratados acerca de estas materias $^{56}$. Esta posición plantea que la Constitución consagra el derecho de sindicación y la libertad sindical negativa ${ }^{57}$, y también la libertad sindical positiva, perspectiva que se ve reforzada por los tratados internacionales respecto de la materia ${ }^{58} \mathrm{y}$, la autonomía sindical, a base de la declaración expresa del inciso final del n. 19 como por lo dispuesto en el Art. 1. de la Constitución, en orden a establecer la autonomía de los grupos intermedios para cumplir sus propios fines ${ }^{59}$. Esta posición es compartida en términos similares a los expuestos ${ }^{60}$, en cuanto afirma que la Constitución garantiza expresamente las manifestaciones más relevantes de su contenido y que comprenden no solo el derecho de organización y afiliación, sino también el que aquí hemos denominado derecho de actividad sindical, como el derecho de negociación colectiva y buelga ${ }^{61}$.

Sin embargo, la segunda tesis rechaza la consagración de los derechos de libertad sindical en el texto original ${ }^{62}$, afirmando que la Constitución ....se limita a reconocer de modo fragmentario ciertas manifestaciones de tal derecho, dejando de manifiesto una concepción del mismo que lo limita al derecho de sindicación ${ }^{63}$, y si bien se agrega el derecho de negociación colectiva, este se limita a la empresa y respecto del derecho de buelga, antes que reconocerlo previamente, lo probíbe respecto de numerosas personas ${ }^{64}$. Sin embargo, ello no significa la falta de reconocimiento de estos derechos, en cuanto a partir de la modificación constitucional de 1989 y debido a lo establecido en el Artículo $5^{\circ}$ inciso segundo, se incorporarían los derechos de libertad sindical establecidos en tratados internacionales, ratificados por Chile y que se encuentren vigentes.

Así, para este sector de la doctrina laboralista la incorporación de los derechos de la libertad sindical se plantea desde la modificación constitucional de $1989^{65}$ sobre la base de los tratados ya ratificados de tales materias ${ }^{66} \mathrm{y}$, mayoritariamente, a partir de

${ }^{56}$ La de Gamonal, S. (Introducción al Derecho del Trabajo, Editorial Cono Sur, Santiago, 1998, 231 páginas) y Ugarte, J.L. ("Libertad Sindical y Constitución: Cómo superar una vieja lectura”, en Revista Laboral Chilena, Mayo 2000, pp. 69-79).

57 Gamonal, S., Introducción..., cit., p. 57

${ }^{58}$ Gamonal, S., Introducción..., cit., pp. 58 y 59.

59 Gamonal, S, Introducción..., cit., p. 61.

${ }^{60}$ Ugarte, J.L. cit., pp:69-79.

${ }^{61}$ Ugarte, J.L. cit., pp. 75-76.

62 Planteada, entre otros, por Toledo. C. (Tutela de Libertad Sindical, Ed. Thomson Reuters, Santiago, 2013, pp. 32-36) y Tapia F. ("El reconocimiento constitucional de la libertad sindical y el derecho de negociación colectiva”, en Dirección del Trabajo [editor] Negociación colectiva en Chile. La debilidad de un derecho imprescindible, Edita Dirección del Trabajo, Santiago, 2008, pp. 149-171).

63 Toledo, cit., pp. 32-33.

${ }^{64}$ Ibid.

${ }^{65}$ En este sentido, Tapia F., cit., p. 151.

${ }^{66}$ A esa fecha han sido ratificados dos Tratados generales: la Carta de Naciones Unidas sobre Derechos Humanos, de 1947 y el Pacto de Derechos económicos, Sociales y Culturales, 
la ratificación de los Convenios de libertad sindical de la OIT, de 1998, ya sea porque incorporan tales derechos ${ }^{67}$, ya sea porque agregan una valiosa fuente de bermenéutica constitucional y por el reconocimiento amplio que la Constitución hace de la libertad sindical ... dicha amplitud se vuelve muy difícil de discutir ${ }^{68}$.

\section{El CONTENIDO DE LOS DERECHOS DE LIBERTAD SINDICAL EN LA CONSTITUCióN}

A causa de la diversidad de posiciones que fundamentan el reconocimiento de los derechos de libertad sindical en la Constitución chilena, se plantea la interrogante referida a la incidencia que tendría dicha diversidad en la fundamentación y en el contenido de los derechos sindicales.

Respecto del derecho de sindicación ${ }^{69}$, y desde la perspectiva del principio de la libertad sindical, se presentan dos contenidos del mismo, que si bien no difieren en lo sustancial, sí plantean distinciones tanto en la fundamentación normativa como en la restricción constitucional a una actividad: la de que las organizaciones sindicales no podrán participar en actividades político partidistas (Art. 19, $\mathrm{n}^{\circ}$ 19, inciso final, C.P.). En primer término, la tesis del reconocimiento explícito ${ }^{70}$ plantea que se acoge el contenido del derecho de sindicación en conformidad a la libertad sindical, en cuanto acoge tanto la dimensión de la libertad individual negativa como positiva (Art. 19, n19 C.P.), además de la autonomía sindical, en cuanto la Constitución ordena que la ley contemplará los mecanismos que garanticen la autonomía de estas organizaciones (Art. 19, $\mathrm{n}^{\circ} 19$, inciso $3^{\circ}$ ); reforzaría esta posición lo dispuesto en el Art. $1^{\circ}$ de la Constitución en cuanto garantiza a los grupos intermedios la adecuada autonomía para cumplir sus propios fines. De otra parte, la tesis que agrega al contenido original de la Constitución el de los Tratados sobre derechos humanos plantea que dicho contenido comprende los siguientes derechos ${ }^{71}$ : (a) El derecho a fundar organizaciones sindicales sin autorización previa (texto original de la Constitución). (b) La libertad de afiliación y de desafiliación a una organización

${ }^{67}$ En este sentido, Tapia, F. en cuanto ...ya no se trata de derechos constitucionales aislados, sino más bien, de un bloque constitucional de derechos de libertad sindical, especialmente con la ratificación de los convenios básicos de libertad sindical... (cit, p. 151).

${ }^{68}$ Ugarte, J.L., cit., p. 76.

${ }^{69}$ Cuyo texto literal establece:

$19^{\circ}$.- El derecho de sindicarse en los casos y forma que señale la ley. La afiliación sindical será siempre voluntaria.

Las organizaciones sindicales gozarán de personalidad jurídica por el solo becho de registrar sus estatutos y actas constitutivas en la forma y condiciones que determine la ley.

La ley contemplará los mecanismos que aseguren la autonomía de estas organizaciones. Las organizaciones sindicales no podrán intervenir en actividades político partidistas.

${ }^{70}$ Gamonal, S., Introducción... cit., pp. 57-61,

71 Toledo, C., La negociación colectiva en la Constitución de 1980, Tesis para optar al Grado de Magíster en Derecho Público con Mención en Derecho Constitucional, P. Universidad Católica de Chile. Santiago 2002, pp. 103-106. 
sindical ya fundada (texto original de la Constitución). (c) El derecho de las organizaciones sindicales a establecer sus propios fines, lo que deriva de la autonomía de cuerpos intermedios (garantizado en el Art. 1 de la Constitución y complementado por el contenido de los Convenios 87 y 98). (d) El derecho a ejercer la actividad sindical en forma autónoma; planteando la duda del límite constitucional a las actividades político partidistas, establecidas en el inciso final del n. 19.

De igual manera, respecto del derecho de negociación colectiva en la Constitución ${ }^{72}$, se plantean dos alcances de su contenido, en razón de las dos tesis que fundamentan los derechos sindicales en la Constitución. Uno de ellos, constituido por una de las posiciones de la primera tesis, reitera los específicos contenidos señalados en el texto constitucional sin confrontarlos con los convenios de OIT; dicha posición de la tesis del reconocimiento explícito ${ }^{73}$ desarrolla el contenido de este derecho sobre la base del texto constitucional y presenta los siguientes alcances ${ }^{74}$ : (a) Respecto de la titularidad y cobertura, este constituye un derecho de los trabajadores en el ámbito de la empresa, incorpora a los trabajadores de la función pública y las materias de negociación son las de carácter laboral. (b) Respecto de la remisión a la ley, reitera que la Constitución mandata al legislador en orden a que establezca las modalidades de la negociación colectiva y los procedimientos adecuados para lograr en ella una solución justa y pacífica y, de igual manera, mandata al legislador la definición de los casos en que la negociación colectiva deba someterse a arbitraje obligatorio, el que corresponderá a tribunales especiales de expertos. La segunda tesis plantea los siguientes contenidos en conformidad a los tratados acerca de libertad sindical: (a) el derecho de los trabajadores es con la empresa en que laboran, sin embargo en conformidad con el principio de libertad sindical es discutible la limitación del derecho al ámbito de la empresa ${ }^{75}$, en cuanto la determinación del nivel de negociación debería depender esencialmente de la voluntad de las partes ${ }^{76}$. (b) La ley expresamente debe establecer los casos en que no se permita negociar ${ }^{77}$, sin embargo, el legislador no es enteramente libre, en cuanto que ...no puede afectar la esencia del derecho a negociar colectivamente afectando al mismo tiempo la autonomía sindical, ni imponerle condiciones o requisitos que impidan el libre ejercicio de tales derechos, toda vez que el Comité de Libertad sindical ha planteado que el derecho de negociar libremente con los empleadores las condiciones de trabajo constituye un elemento esencial de la libertad sindical ${ }^{78}$. (c) La ley establecerá las

${ }^{72}$ Cuyo texto en el art. 19 , n. 16 inciso $5^{\circ}$, plantea:

La negociación colectiva con la empresa en que laboren es un derecho de los trabajadores, salvo los casos en que la ley expresamente no permita negociar. La ley establecerá las modalidades de la negociación colectiva y los procedimientos adecuados para lograr en ella una solución justa y pacífica. La ley señalará los casos en que la negociación colectiva deba someterse a arbitraje obligatorio, el que corresponderá a tribunales especiales de expertos cuya organización y atribuciones se establecerán en ella.

73 En cuanto la segunda posición no presenta un desarrollo del contenido de este derecho.

${ }^{74}$ Irureta, P., cit, pp. 157-184.

75 Toledo, C. "La negociación...", cit., pp. 109-112.

${ }^{76}$ Comité de Libertad Sindical, cit., p. 184.

77 Toledo, C. “La negociación...”, cit., pp. 109-112.

78 Comité de Libertad Sindical, cit., p. 171. 
modalidades de la negociación colectiva y los procedimientos adecuados para lograr en ella una solución justa y pacífica. (d) La ley señalará los casos en que la negociación colectiva deba someterse a arbitraje obligatorio, el que corresponderá a tribunales especiales de expertos cuya organización y atribuciones se establecerán en ella.

Respecto del derecho de huelga es que se ha planteado una mayor discusión acerca de su fundamentación y, en menor medida, en comparación con su contenido. Debido a que el tenor literal del precepto constitucional prohíbe la huelga en determinados supuestos $^{79}$, ¿cuál es el fundamento de su configuración como derecho? En la doctrina laboralista las tesis van desde el reconocimiento implícito, pasando por la tesis dogmáti$c a^{80}$, hasta su incorporación por vía de los tratados internacionales.

La tesis del reconocimiento implícito fue tempranamente defendida. En efecto, ya en 1989 se plantea que si la huelga está prohibida para concretas categorías de trabajadores y de actividades ... a contrario sensu, corresponde entender que los demás trabajadores no incluidos en tal probibición tienen el derecho asegurado por la Constitución de declarar y hacer efectiva la buelga ${ }^{81}$; esta posición ha sido posteriormente asumida por otros autores ${ }^{82}$. La tesis dogmática plantea que el derecho de huelga se reconoce expresamente en la Constitución a partir del reconocimiento expreso que esta hace de la autonomía sindical como derecho constitucional, en cuanto esta autonomía comprende todos los elementos de la libertad sindical (...) y por tanto la buelga como derecho de los trabajadores está expresamente consagrada en la Constitución ${ }^{83}$. Finalmente la tesis del reconocimiento del derecho por ratificación de los tratados concernientes a derechos humanos plantea, precisamente, que la incorporación de los tratados de derechos humanos y de libertad sindical han significado el reconocimiento del derecho de huelga en el texto constitucional ${ }^{84}$, a base del Pacto de Derechos Económicos Sociales y culturales, el que establece expresamente este derecho ${ }^{85}$, o reconocido por los convenios de la OIT ${ }^{86}$.

${ }^{79}$ No podrán declararse en buelga los funcionarios del Estado ni de las municipalidades. Tampoco podrán bacerlo las personas que trabajen en corporaciones o empresas, cualquiera que sea su naturaleza, finalidad o función, que atiendan servicios de utilidad pública o cuya paralización cause grave daño a la salud, a la economía del país, al abastecimiento de la población o a la seguridad nacional. La ley establecerá los procedimientos para determinar las corporaciones 0 empresas cuyos trabajadores estarán sometidos a la probibición que establece este inciso...

${ }^{80} \mathrm{Al}$ respecto, véase de Gamonal, S., "El derecho de huelga en la Constitución chilena”, Revista de Derecho, Universidad Católica del Norte, Año 20, Nº 1, 2013.

${ }^{81}$ Macchiavelo, G., Derecho Colectivo del Trabajo. Teoría y Análisis de sus normas, Editorial Jurídica de Chile, Santiago, 1989, p. 443.

${ }^{82}$ En este sentido, Irureta, P. (cit., p. 187) y Caamaño, E. y Ugarte, J.L., Negociación Colectiva y Libertad Sindical. Un enfoque crítico, Santiago de Chile, Ed., LegalPublishing, p. 78.

${ }^{83}$ Gamonal, S., "El derecho de huelga...", cit., 121.

${ }^{84}$ Tapia, F. cit, pp. 160-167.

${ }^{85}$ En cuanto establece que Los Estados Partes se comprometen a garantizar: d) El derecho a huelga ejercido de conformidad con las leyes de cada país (Art. 8, n|, d).

${ }^{86}$ Acerca del contenido del derecho de huelga en los Convenios de la OIT, véase de Gernigon B, Odero, A., y Guido H. Principios de la OIT sobre el Derecho de Huelga, Ed. Oficina Internacional del Trabajo, Ginebra, 2000, 64 páginas. 


\section{LAS LimitaCiONES DE LA CONSTITUCión EN LA GARANTía DE LOS DERECHOS DE LIBERTAD SINDICAL}

Cualquiera sea la posición adoptada por la doctrina laboralista chilena, todas están conforme en el reconocimiento constitucional de los derechos de libertad sindical, sea porque el modelo constitucional original comprende tales derechos, sea porque han sido incorporados mediante la ratificación de tratados internacionales sobre derechos fundamentales de carácter laboral.

Sin embargo estos derechos de libertad sindical tienen un escaso reconocimiento en el ámbito de las relaciones laborales, ya sea por el desconocimiento que la ley laboral efectúa de tales derechos, ya sea por la abierta contradicción que la misma ley plantea respecto del derecho en cuestión.

Al efecto deben considerarse los dos planos en los que opera el supuesto carácter constitucional de los derechos de libertad sindical: uno es pertinente a la definición del modelo normativo de relaciones laborales y la regulación que establece y el otro es su reconocimiento en la controversia que sea sometida a tribunales.

Respecto del modelo normativo de relaciones laborales, este es de carácter heterónomo en cuanto es definido básicamente por la ley laboral, la que tiene su origen en la regulación impuesta por el Plan Laboral, por medio de los Decretos leyes 2756, sobre organización sindical, y 2758, sobre negociación colectiva, ambos de julio de $1979^{87}$. Las orientaciones básicas de este modelo normativo es limitar la acción de las organizaciones de trabajadores al ámbito de la empresa y a las materias de carácter económico. Para ello se rigidizó la normativa sindical, regulando con gran detalle cada una de las instituciones jurídico laborales y estableciendo, además, limitaciones y prohibiciones respecto de las organizaciones sindicales, de la negociación colectiva y de la huelga, excluyendo además al conflicto colectivo.

Si bien es cierto que este modelo legal ha tenido modificaciones que se han efectuado mediante sucesivas reformas laborales, la de 1991 y las del $2001^{88}$, estas han sido de carácter marginal que han depurado el modelo, pero que mantienen las bases del modelo

${ }^{87}$ El modelo normativo de relaciones laborales que el régimen militar impuso hacia fines de la década del setenta se inserta en un proyecto de cambio radical a diversas áreas de la institucionalidad económica y social del país, proceso que denominó “modernizaciones”, y que incorporó además del área laboral, el de educación, el de salud y el régimen previsional en el campo de la seguridad social, entre otras. En el ámbito de las relaciones laborales el cambio del modelo normativo comprendió tanto las relaciones laborales individuales como las colectivas, dictándose para su objetivo diversos textos legales que, a la vez de suprimir la legislación hasta entonces vigente, establecieron el nuevo marco normativo; entre los principales textos legales deben considerarse el D.L. 2.200 de 1978 sobre Contrato de Trabajo y de Protección a los Trabajadores, D.L. 2.756 de 1979 sobre organizaciones sindicales, D.L. 2.758 de 1979 sobre negociación colectiva y Ley 18.018, la que principalmente modificó al D.L. 2.200.

${ }^{88}$ La primera reforma laboral es la que se efectuó en los inicios del nuevo sistema democrático, y que en la perspectiva del Derecho sindical involucró la Ley 19.049, sobre centrales sindicales, y la Ley 19.069, sobre organización sindicales y negociación colectiva; ambas leyes son de 1991. Mientras que la segunda reforma laboral se efectuó por medio de la Ley 19.759, de 2001, sobre diversas materias laborales que involucraron a la organización sindical y a la negociación colectiva. 
del Plan Laboral, manteniendo contradicciones con los contenidos de la libertad sindical ${ }^{89}$. Una situación especial plantea el derecho de sindicación de funcionarios públicos, en cuanto si bien se les ha reconocido el derecho de constituir asociaciones de funcionarios, no se les reconoce el derecho de negociar colectivamente, y a nivel constitucional se les prohíbe el ejercicio del derecho de huelga ${ }^{90}$.

Los órganos de control de aplicación de convenios de OIT, como son la CEACR y el CLS, han planteado diversas vulneraciones a los convenios de libertad sindical por parte del ordenamiento jurídico chileno ${ }^{91}$; así, entre otras, respecto del nivel de negociación colectiva ... la legislación no debería obstaculizar la negociación colectiva a nivel de industria (caso CLS, 1096 de 1982), que la prohibición general de huelga durante la vigencia de un acuerdo colectivo o respecto de los funcionarios públicos ...sería contraria a los principios de libertad sindical (caso CLS, 823 de 1978) o que el derecho de huelga no debería limitarse a conflictos de trabajo susceptibles de finalizar en un convenio colectivo determinado (caso CLS, 2814 de 2013).

Cierto es que el legislador chileno ha efectuado algunas específicas modificaciones con el fin de supuestamente adecuar la legislación laboral al principio de libertad sindical, pero la modificación no alcanza a cumplir el mínimo requerido. Paradigmática en tal sentido ha sido la modificación de la tipología sindical efectuada por la Ley 19.759 de 2001 en cuanto incorpora la diversidad de sindicatos que puedan constituir las partes ${ }^{92}$, sin embargo niega a los nuevos tipos de sindicatos la titularidad de la negociación colectiva reglada (es decir, con deber de negociar y con derecho de huelga), manteniendo dicha titularidad solo al sindicato de empresa y a la coalición de trabajadores en el mismo nivel.

En cuanto a la aplicación de los derechos constitucionales por parte de los tribunales de justicia con ocasión de las controversias jurídicas que deben conocer, en muchos casos sí se reconoce la vigencia del derecho de libertad sindical, ya sea porque se entiende

89 Acerca de esta materia y en detalle, véase de Rojas M., I. "Las contradicciones entre el modelo normativo de negociación colectiva y el principio de libertad sindical”, en Anuario de Derecho del Trabajo y Seguridad Social, $\mathbf{N}^{\circ}$ 1, 2000, Sociedad Chilena de Derecho del Trabajo y la Seguridad Social, Santiago de Chile, 2000, pp. 119-135.

${ }^{90}$ Concerniente a este tema, véase de Precht, J., "Derecho de sindicación de funcionarios públicos. Análisis de su constitucionalidad". Revista de Derecho de Universidad Austral de Chile, Vol. II No 1-2, diciembre 1991, pp. 21-29

${ }^{91}$ Véase, Martínez, P., Los casos de vulneraciones a la libertad sindical cometidas por Chile, conocidas por el Comité sindical de la OIT, Tesis de Magíster en Derecho del Trabajo y de la Seguridad Social, Universidad de Talca, Chile, y Universidad de Valencia, octubre de 2013.

${ }^{92}$ El Fundamento de esta medida lo indica el Proyecto de Ley (Congreso Nacional, Historia de Ley 19.759

http://www.bcn.cl/historiadelaley/nc/lista-de-resultado-de-busqueda/Ley\%2019759/, visitado el 21 de octubre de 2015, p.10): El proyecto, en primer lugar, propone hacer posible, en la forma más amplia, el derecho de sindicalización de los trabajadores, reconociéndoseles una mayor amplitud en los tipos de sindicatos bajo los cuales se pueden reunir.

De abi que propone cambiar el criterio restrictivo que actualmente se contiene en el artículo 216 del Código del Trabajo, por una enumeración no taxativa de ellos, que reconozca expresamente su derecho a organizarse de la forma que parezca más adecuada a la representación de sus intereses, tanto en los tipos de sindicatos como en su estructura y fines. 
incorporado al texto constitucional, ya sea porque lo establece el tratado sobre derechos fundamentales ratificado por el Estado de Chile. Y ello más allá del instrumento de tutela establecido por la misma Constitución, es decir, el recurso de protección, el que además de su procedencia restrictiva en el ámbito de los derechos sindicales - procede solo respecto de los del Art. 19, $\mathrm{n}^{\circ} 19$ - ha tenido escasa aplicación en dicho ámbito ${ }^{93}$; sino que dichos pronunciamientos han sido resultado de acciones ordinarias y, particularmente en el último período, por la acción de tutela ante prácticas antisindicales.

En algunos casos el Derecho internacional colabora en la interpretación de la norma laboral en conformidad al principio de libertad sindical, como fue la primera sentencia dictada por la Corte Suprema después de haberse ratificado los convenios de Libertad Sindical de la OIT, con el fin de hacer extensivo el fuero laboral al período previo de constitución del sindicato ${ }^{94} \mathrm{o}$, varios años después, para aplicar el arresto con motivo de una práctica antisindical ${ }^{95}$.

En otros casos los tribunales reconocen la vigencia del derecho de libertad sindical de que se trata, particularmente el de huelga.

La primera discusión se plantea respecto del derecho de huelga en el estricto marco que es reconocido por la ley laboral, es decir, el de la modalidad de la negociación colectiva reglada, en cuanto, a partir de la reforma efectuada por la Ley 19.759, de 2001 , se imponen condiciones para que proceda el reemplazo de trabajadores huelguistas $^{96}$ y la discusión jurídica es si la exigencia procede solo respecto del reemplazo externo -trabajadores de fuera de la empresa, que deberían ser contratados al efecto- o también del reemplazo interno -trabajadores de la misma empresa a los que se les imponen ocupar el puesto del trabajador huelguista-. Pues bien, la jurisprudencia de la Corte Suprema de los últimos años mantuvo la posición de que la norma legal solo prohibía el reemplazo externo ${ }^{97}$. Sin embargo a partir de diciembre de 2014 mantiene una tesis distinta ${ }^{98}$, toda vez que una interpretación sistémica debe considerar tanto las modificaciones de la norma legal in comento -el citado artículo 38- (considerandos 13 a 16) y las normas del suministro que prohíben el contrato de puesta a disposición para reemplazo de huelguistas (considerando 24) como del reconocimiento implícito del derecho de huelga en la Constitución (considerando 23) y su reconocimiento directo en los tratados internacionales (considerandos 17 a 20), por lo que se rechaza tanto el reemplazo externo como interno.

\footnotetext{
93 Gamonal, S. "El Derecho del trabajo y la acción de protección”, en Revista de Derecho Universidad de Concepción, número 209 enero-junio 2001, página 111.

94 Sentencia de Corte Suprema (en adelante S.C.S.), de19 de octubre de 2.000, Rol 3394 de 2000, pronunciado en recurso de casación.

95 Como fundamenta la S.C.S. de 15 de junio de 2009, Rol, 3779-09 (pronunciada en apelación de recurso de protección).

96 Art. 381 del C.T.

97 Por todas, S.C.S. de 7 de marzo de 2013, 4936 de 2012, pronunciada en recurso de unificación de jurisprudencia.

${ }^{98}$ S.C.S de 5 de diciembre de 2014, Rol 3.514-2.014, pronunciada en recurso de unificación de jurisprudencia.
} 
La segunda discusión se plantea respecto del reconocimiento del derecho de huelga fuera de la negociación colectiva reglada, es decir, en el ámbito de un conflicto colectivo. Además de que las sentencias que admiten la huelga a propósito de un conflicto colectivo son recientes, la misma doctrina que emana de estas sentencias es de carácter limitada en cuanto se han pronunciado respecto de la procedencia de la terminación del contrato por las inasistencias al trabajo. En efecto, cuando se trata de trabajadores aforados es que el ejercicio del derecho de huelga impide la terminación de su contrato, mientras que si se trata de trabajadores sin fuero laboral solo se tutela la calificación del despido, de uno de carácter justificado a otro que es injustificado.

Así, en el caso del ejercicio del derecho de huelga de un trabajador protegido por el fuero sindical, toda vez que se trata de un director sindical, se rechaza la solicitud de desafuero en cuanto la inasistencia al trabajo argumentada por el empleador respondió al ejercicio del derecho de huelga en el marco de un conflicto colectivo en el que se ejerce el derecho de huelga, derecho que es reconocido implícitamente en la Constitución ${ }^{99}$.

En los demás casos en que se ha reconocido el derecho de huelga con ocasión de un conflicto colectivo ${ }^{100}$, aunque no siempre se la da tal denominación ${ }^{101}$, se concluye que la inasistencia al trabajo es de carácter justificada en cuanto se debió a un conflicto colectivo en el que se ejerció el derecho de huelga, por lo que el despido es de carácter injustificado, ordenando por consiguiente la indemnización de tal carácter.

Ciertamente que en estos últimos casos el nivel de protección ante el ejercicio de un derecho fundamental es bastante precario en cuanto de igual manera se materializa la decisión de terminación del contrato y se violenta uno de los bienes laborales más preciados, y que es el puesto de trabajo, en circunstancias de que la readmisión constituye la condición necesaria para la tutela de los derechos fundamentales ${ }^{102}$. Podría señalarse en contra que la respectiva demanda fue la de declaración de despido injustificado y de la consiguiente indemnización, por lo que el juzgador no tenía otra alternativa. Ello es cierto y al menos desde el 2008, con la entrada en vigencia de la reforma procesal

99 Rancagua, cinco de enero de dos mil doce, Rol 159 de 2011, pronunciado en recurso de nulidad, Considerando $5^{\circ}$.

100 Sentencia de Corte de Apelaciones (en adelante S.C.A.) de San Miguel, de 9 de julio de 2014, Rol 183 de 2014, pronunciada en recurso de nulidad, en cuanto la huelga es parte integrante de la libertad sindical (considerando quinto, primer párrafo), que en la Constitución solo se niega el derecho de huelga a los funcionarios del Estado y de las municipalidades considerando quinto, segundo párrafo),

${ }^{101}$ En la S.C.A. de Concepción, de 21 de noviembre de 2001, que conoce en Recurso de Apelación, se comparte el criterio del juez de instancia en cuanto que: ...cabe concluir que si bien es cierto los demandantes se negaron a trabajar en las faenas convenidas en el contrato de trabajo, también lo es que dicha negativa es justificada, como bien lo resolvió el juez a quo en el considerando décimo de la sentencia en revisión, y cuyos argumentos comparten estos sentenciadores, por cuanto se produjo en un contexto de defensa de sus derechos laborales, al reclamar un aumento de sus remuneraciones, de manera que existe una causa o un motivo plausible para no realizar las labores convenidas. (considerando 16).

102 Marzi, D., "La readmisión como reparación: condición para la ciudadanía en el trabajo o la importancia de poder ejercer derechos", en Squella, A., y Arriagada, Ma.B. (directores), Revista de Ciencias Sociales, Número Monográfico “Sobre los Derechos Sociales”, Ed. Edeval, Valparaíso, 2015, pp. 513-552. 
laboral, se podría demandar la reincorporación mediante una acción de tutela por lesión al derecho de libertad sindical con ocasión del despido ${ }^{103}$.

La tercera discusión se plantea con ocasión del ejercicio de la huelga en la administración pública y de las municipalidades. Si bien las tesis que plantean el fundamento de los derechos de libertad sindical en el mismo texto constitucional -sea a base de la del reconocimiento implícito o de la autonomía sindical- no dan cuenta de este fundamento, se ha señalado por la tesis del reconocimiento de los derechos de libertad sindical por vía de la ratificación de convenios internacionales, es que este derecho sí se reconocería respecto de estos funcionarios ${ }^{104}$, más aún si el conflicto colectivo se plantea con ocasión de la negociación colectiva, en cuanto el Convenio 151, ratificado por el Estado de Chile.

Sin embargo, esta discusión no ha llegado en tales términos a los tribunales de justicia, sino que las acciones responden a las medidas efectuadas por la autoridad estatal frente a las paralizaciones de faenas que conlleva el ejercicio de la huelga, las que mayoritariamente han consistido en descuento de las remuneraciones por los días no trabajados, y lo que se discute en tribunales es la procedencia de este descuento no tanto por tratarse del ejercicio de un derecho fundamental, sino porque el descuento se efectuó sin el proceso debido ${ }^{105}$.

\section{REFLEXIONES ACERCA DE LA FALTA DE EFICACIA DE LOS DERECHOS CONSTITUCIONALES DE LIBERTAD SINDICAL}

En definitiva, de acuerdo con las tesis planteadas por la doctrina laboralista, la Constitución reconocería los derechos de libertad sindical. Sin embargo, se plantean dos particularidades en la eficacia de las normas constitucionales en la materia. De una parte, este reconocimiento no se ha verificado en el modelo legal, por lo que estaría pendiente el cumplimento del compromiso del Estado de adecuar la normativa legal de las relaciones colectivas de trabajo a los mandatos constitucionales y las obligaciones internacionales tras la ratificación de tratados concernientes a la materia. De otra parte, aunque el modelo desconozca los derechos referidos, la doctrina de los tribunales de justicia sí los reconoce, pero se plantearían problemas en la eficacia de estos derechos en cuanto el instrumento de tutela cede ante el despido laboral.

Sin embargo ¿es que son incuestionables estas tesis que admiten el reconocimiento de los derechos de libertad sindical en la Constitución? La falta de eficacia de estas normas constitucionales respecto del modelo legal de relaciones laborales permitiría reiterar dicha interrogante y, consiguientemente, revisar las tesis planteadas hasta ahora.

103 Artículos 489 en relación con el 294, ambos del C.T.

104 Tapia, F. cit, p. 166.

105 Por todas, véase S.C.A. de Santiago, de 16 de septiembre de 2011, Rol 544 de 2011, pronunciada en recurso de apelación.

Con relación a esta sentencia véase de Muñoz L. F. "ANEF con SII: ¿Libertad sindical, debido proceso o libertades públicas?”, en Revista Ius et Praxis, Año 17, n² 2, pp. 537-550. 
La tesis que plantea el reconocimiento directo de tales derechos por parte de la Constitución, y más allá de las diferencias que plantean las diversas posiciones al interior de la misma, es cierto que independientemente de la interpretación extensiva que hace de los preceptos de la Constitución, esta tesis presenta carencias y contradicciones.

En primer lugar, el concepto que maneja de libertad sindical no es el de carácter universal -que es el acordado por los Estados y las partes sociales al interior de la OIT - , en cuanto una de las posiciones no confronta dicho contenido con el de la OIT y la otra no se hace cargo de las contradicciones del modelo constitucional con el principio de libertad sindical, como son: (1) limitar el reconocimiento del derecho de negociación colectiva al ámbito de la empresa, en circunstancias que es de su esencia el derecho de las partes sociales de negociar colectivamente en el ámbito que ellas decidan y que es compromiso del respectivo Estado la de promover la negociación colectiva en los diversos niveles de la estructura de negociación; (2) exclusión de diversas categorías de trabajadores del derecho de huelga, y (3) marginación de las organizaciones sindicales de intervenir en "actividades político partidistas".

En segundo término, si se sostiene la conformidad de la Constitución con el principio de libertad sindical pero la disconformidad con el modelo legal, este último sería inconstitucional, y ello no ha sido alegado hasta ahora. Pero independientemente pues esta falta no permite extraer conclusión alguna, ¿es que el modelo legal de regulación de las relaciones colectivas de trabajo es inconstitucional? Sería bastante difícil admitirlo, pues es un único modelo de relaciones colectivas de trabajo que se instaura conjuntamente en la Constitución y en la ley laboral por medio de textos normativos consecutivos -los Decretos Leyes 2755, 2756 y 2758, todos de julio de 1979 y que constituyen el Plan Laboral - y que define similares bases normativas: el sindicato sujeto al intervencionismo legal, la negociación colectiva limitada al nivel en la empresa y a materias de carácter económico, el desconocimiento del conflicto colectivo y la consiguiente restricción de la huelga a la controversia de carácter económico en el ámbito de la empresa.

Por su parte, la tesis del reconocimiento constitucional de los derechos de libertad sindical por vía de la ratificación de los convenios sobre derechos humanos ha sido admitida por parte de la doctrina laboralista sin cuestionar su fundamentación y aplicación. En efecto, este sector de la doctrina no ha asumido la discusión tanto doctrinaria como jurisprudencial del valor de los tratados internacionales sobre derechos humanos ${ }^{106}, \mathrm{y}$ que en la actualidad plantea dos interpretaciones: uno es la supremacía constitucional sobre dichos tratados y la otra, que debe distinguirse entre el tratado y los derechos esenciales que ella contienen y que tales derechos sí serían constitución material ${ }^{107}$.

Es cierto que independientemente del nivel que tengan los tratados sobre derechos humanos en la jerarquía normativa, estos constituyen norma para resolver la controversia

106 Tocante a esta discusión, y por todos, Galdamez, L. "El valor asignado por la jurisprudencia del Tribunal constitucional a la jurisprudencia de la Corte Interamericana de Derechos Humanos", en Revista de Estudios Constitucionales, Año 12, N 1, 2014, pp. 329-364.

${ }^{107}$ Galdamez, L. cit., p. 333. 
y así han sido invocados en las sentencias de los tribunales de justicia ${ }^{108}$. Pero el problema que plantea esta tesis es que deja incólume el modelo normativo de relaciones laborales vigente que violenta los derechos de libertad sindical, toda vez que el Estado no ha asumido o no ha podido dar respuesta a los compromisos adquiridos de adecuar la normativa nacional a los requerimientos del Derecho internacional.

Precisamente, una connotación que plantea la doctrina del Derecho internacional sobre derechos humanos es que plantea un efecto directo de sus normas en el derecho interno, solucionando de esta manera la pereza con que los respectivos poderes legislativos (pueden) responder a su obligación de adecuar la legislación nacional a las obligaciones asumidas en los tratados internacionales... ${ }^{109}$, y como cuestiona Fuentes ${ }^{110}$, ...porque el derecho internacional (sería) la solución para los problemas que no han podido ser solucionados a través del derecho interno.

Es cierto que en el ámbito laboral el peso del Derecho internacional del trabajo tiene una trayectoria de casi 100 años, específicamente desde el nacimiento de la Organización Internacional del Trabajo, pero la eficacia de sus normas no depende de la posible incorporación al ordenamiento interno, sino, como lo señalan reiteradamente los órganos de aplicación de estas normas, de la adecuación del modelo normativo que esté vigente. Precisamente lo que importa es la definición de un modelo normativo que acoja los requerimientos del principio de libertad sindical, porque las relaciones laborales se desenvuelven en el marco de dicho modelo, el que en el caso chileno presenta una considerable tradición de intervencionismo legal, y que significa que en gran parte estas relaciones colectivas de trabajo respondan a las directrices de este recuadro legal, sin perjuicio de algunas excepciones, como las que muestran algunas experiencias de negociación colectiva fuera de la empresa, pero que ciertamente involucran un alto poder negociador por condiciones no jurídicas sino que sociales o económicas.

Y ciertamente, el problema en definitiva es de índole político en cuanto se debe acordar un modelo que acoja a lo menos los mínimos de libertad sindical, consenso que hasta ahora no se ha dado en nuestro país.

\section{BIBLIOGRAFÍA}

Ackerman, Mario, "Carácter y eficacia de los pronunciamientos de la Comisión de Expertos en la aplicación de convenios y recomendaciones de OIT" (en http://colegioabogadosavo.org. ar/laboral/contenido/documentos/77.pdf, visitado el 10 de agosto de 2016).

Bellace, J., "La OIT y el derecho de huelga", en Revista Internacional del Trabajo, Vol. 133, (014), núm 1

108 Aunque tal explicación excluiría la norma internacional que reconoce como derecho al que está expresamente excepcionado de tal calidad por la Constitución, como es el caso del derecho de huelga de diversas categoría de trabajadores.

${ }^{109}$ Fuentes, X., "El derecho internacional y el derecho interno: definitivamente una pareja dispareja”, en Revista de Economía y Derecho, Universidad Peruana de Ciencias Aplicadas, vol. 15, n 4, pp. 21-35.

${ }^{110}$ Ibid. 
CaAmaño, E. y Ugarte, J.L., Negociación Colectiva y Libertad Sindical. Un enfoque crítico, Santiago de Chile, Ed., LegalPublishing.

Fuentes, X., "El derecho internacional y el derecho interno: definitivamente una pareja dispareja”, en Revista de Economía y Derecho, Universidad Peruana de Ciencias Aplicadas, vol 15, no 4, pp. 21-35.

GALDAMEZ, L. "El valor asignado por la jurisprudencia del Tribunal constitucional a la jurisprudencia de la Corte Interamericana de Derechos Humanos", en Revista de Estudios Constitucionales, Año 12, $\mathrm{N}^{\circ}$ 1, 2014, pp. 329-364.

Gamonal, S., "El derecho de huelga en la Constitución chilena", Revista de Derecho, Universidad Católica del Norte, Año 20, Nº 1, 2013.

Gamonal, S. "El Derecho del trabajo y la acción de protección”, en Revista de Derecho Universidad de Concepción, número 209, enero-junio 2001.

Gamonal, S., Introducción al Derecho del Trabajo, Editorial Cono Sur, Santiago, 1998.

Gernigon, B., Odero, A., y Guido H. Principios de la OIT sobre el Derecho de Huelga, Ed. Oficina Internacional del Trabajo, Ginebra, 2000.

Giugni, G., Diritto Sindacale, Cacucci editore, Bari, 1988, pp. 51.

Irureta, P., Constitución y Orden Público Laboral. Un análisis del art. $19 \mathrm{~N}^{\circ} 16$ de la Constitución chilena, Ed. Universidad Alberto Hurtado, Santiago, 2006, No 9.

LEYTON, Jorge y Azócar, Rodrigo, "El valor jurídico de los pronunciamientos de los órganos de control de la OIT en Chile", Ponencia libre presentada en Cuartas Jornadas de Derecho del Trabajo de la Universidad de Talca: "Los derechos del trabajo en la Constitución, en especial los de libertad sindical", Santiago, 14 y 15 de julio de 2016.

Maestro, G., La constitución del trabajo en el estado social, Ed. Comares, Granada, 2002.

Macchiavelo, G., Derecho Colectivo del Trabajo. Teoría y Análisis de sus normas, Editorial Jurídica de Chile, Santiago.

Martínez, P., Los casos de vulneraciones a la libertad sindical cometidas por Chile, conocidas por el Comité sindical de la OIT, Tesis de Magíster en Derecho del Trabajo y de la Seguridad Social, Universidad de Talca, Chile, y Universidad de Valencia, octubre de 2013.

MARZI, D., "La readmisión como reparación: condición para la ciudadanía en el trabajo o la importancia de poder ejercer derechos", en Squella, A., y Arriagada, Ma.B. (directores), Revista de Ciencias Sociales, Número Monográfico "Sobre los Derechos Sociales", Ed. Edeval, Valparaíso, 2015, pp. 513-552.

MUÑOZ L.F. “ANEF con SII: ¿Libertad sindical, debido proceso o libertades públicas?”, en Revista Ius et Praxis, Año 17, $\mathrm{n}^{\circ} 2$, pp. 537-550.

Palomeque, M., Derecho Sindical Español, Ed. Tecnos, Madrid, Quinta Edición revisada, 1994.

Palomeque, M., Los derechos laborales en la Constitución española, Centro de Estudios Constitucionales, Colección Cuadernos y Debates, n. 28, Madrid, 1991.

Plá, A., "Los sindicatos en Uruguay", en Pasco, M. y Ackerman, M. [coordinadores], Los Sindicatos en Iberoamérica, Ed. Aele, Lima, Perú, 1988.

PreCht, J., "Derecho de sindicación de funcionarios públicos. Análisis de su constitucionalidad". Revista de Derecho de Universidad Austral de Chile, Vol. II Nº 1-2, diciembre 1991, pp. 21-29.

Rojas, I., "La legislación laboral en Chile en el ámbito de las relaciones colectivas de trabajo: control de la autonomía colectiva”, en Revista Ius et Praxis, Año 6, nº 2, 2000.

RojAs, I., "Las contradicciones entre el modelo normativo de negociación colectiva y el principio de libertad sindical", en Anuario de Derecho del Trabajo y Seguridad Social, No 1, 2000, Sociedad Chilena de Derecho del Trabajo y la Seguridad Social, Santiago de Chile, 2000.

SALA, T., "El derecho constitucional a la negociación colectiva", en Casas Ma. E., Durán, F. y Cruz, J., Las transformaciones del Derecho del Trabajo, en el marco de la Constitución española, Ed. La Ley, Madrid, 2009. 
Sala, T., Derecho Sindical, Ed. Tirant lo Blanch, Valencia, 1998.

Supiot, A., "Informe de Síntesis", en Marzal, A. (editor), La buelga hoy en el derecho social comparado, Ed, Bosch, Barcelona, 2005, p. 268.

TAPIA F., "El reconocimiento constitucional de la libertad sindical y el derecho de negociación colectiva", en Dirección del Trabajo (editor), Negociación colectiva en Chile. La debilidad de un derecho imprescindible, Edita Dirección del Trabajo, Santiago, 2008.

Toledo. C., Tutela de Libertad Sindical, Ed. Thomson Reuters, Santiago, 2013.

Toledo, C., La negociación colectiva en la Constitución de 1980, Tesis para optar al Grado de Magíster en Derecho Público con Mención en Derecho Constitucional, P. Universidad Católica de Chile. Santiago 2002.

Ugarte, J.L., "El trabajo en la Constitución chilena”, en Bassa, J., Ferrada, J.C., y Viera, C., (editores), La Constitución chilena, Santiago, 2015, pp. 121-140.

Ugarte, J.L., "Libertad Sindical y Constitución: Cómo superar una vieja lectura", en Revista Laboral Chilena, mayo 2000.

\section{Documentos}

Chile, Historia de Ley 19.759, Congreso Nacional, http://www.bcn.cl/historiadelaley/nc/listade-resultado-de-busqueda/Ley\%2019759/, visitado el 21 de octubre de 2015.

Chile, Actas de la Comisión Ortúzar (http://www.leychile.cl/Consulta/antecedentes_const_1980, visitada el 21 de octubre de 2015).

OIT, Reunión Tripartita relativa al Convenio sobre la libertad sindical y la protección del derecho de sindicación 1948 (núm. 87) en relación con el derecho de huelga y las modalidades y prácticas de la huelga a nivel nacional, Ginebra, 23-25 de febrero de 2015 (http://www. ilo.org/wcmsp5/groups/public/---ed_norm/---relconf/documents/meetingdocument/ wcms_346766.pdf, visitado el 10 de agosto de 2016).

OIT, Centro Internacional de Formación de OIT, "Derecho Internacional del Trabajo y Derecho Interno. Manual de Formación para jueces, juristas y docentes en derecho” (Director) Xavier Beaudonet, Ed. Centro Internacional de Formación OIT. Turín, 2009 [en http:// es.slideshare.net/GabrielBenavides/dit-y-derecho-interno-manuel-de-formacion-para-juecesy-juristas-8638515, visitado el 10 de agosto de 2016],

OIT, Comité de Libertad Sindical, La Libertad Sindical (recopilación de decisiones y principios del Comité de Libertad Sindical del Consejo de Administración de la OIT), Quinta edición revisada, Oficina Internacional del Trabajo, Ginebra, 2006.

OIT, Comisión de Expertos en la Aplicación de Convenios y Recomendaciones (Conferencia Internacional del Trabajo), 81.a reunión, 1994, Informe III (Parte 4B), Ginebra, Edita Oficina Internacional del Trabajo, 1994. 
